This is an Accepted Manuscript of an article to be published by Taylor and Francis in Higher Education Research and Development.

\title{
Student Learning Approaches in the UAE: The case for the achieving domain
}

James McLaughlin (corresponding author)

Higher Colleges of Technology, PO Box 25035, Abu Dhabi, United Arab Emirates

Phone: $\quad 971(0) 501086939$

Email: $\quad$ imclaughlin@hct.ac.ae

Philip Durrant

University of Exeter, Baring Court, St. Luke's Campus, Heavitree Road, Exeter, EX1 2LU, UK Phone: $\quad 44$ (0) 1392724974

Email: $\quad$ P.L.Durrant@exeter.ac.uk 


\begin{abstract}
:
The deep versus surface learning approach dichotomy has dominated recent research in student learning approach dimensions. However, the achievement dimension may differ in importance in nonWestern and vocational tertiary settings. The aim was to assess how Emirati tertiary students could be characterized in terms of their learning approaches. The study looked into emergent learning factors that may be important in Emirati students. The students were Emirati men in a first year English for academic purposes program at a tertiary college $(\mathrm{N}=252)$. The students completed the Revised Study Process Questionnaire (R-SPQ-2F) to determine learning orientation along the deep and surface approach dimensions. A factor analysis was carried out to assess emergent dimensions in the data. The results on the deep and surface dimensions were inconclusive. However, the factor analysis suggested a disposition towards a construct that we characterize as 'attainment of satisfaction from learning.' In addition, the factor analysis suggested the possibility of the achieving domain emerging as a separate construct from the surface domain in this context, contrasting with previous research employing the RSPQ-2F. The results suggest that the deep versus surface learning approach model may not sufficiently represent the complexity of student motivations and strategies in the current context. In addition, student affect tied to outcomes is discussed as an important though perhaps overlooked dimension in non-Western contexts. The implications of the results to future research are considered.
\end{abstract}

Key Words: RSPQ-2F, SPQ, leaning, approaches, deep, surface, achieving, United Arab Emirates, UAE, Emirati, tertiary 


\section{1) Introduction}

The deep versus surface learning approach construct represents an attempt to categorize student motivation and strategies towards learning. According to this construct, students who are deeply oriented have intrinsic learning motivation and employ strategies for content mastery. Students who are surface approach oriented, conversely, employ strategies for short term recall and content reproduction. Such students tend to be motivated by external factors such as grades (Biggs, 1987; Entwistle and McCune, 2004).

Biggs, Kember and Leung (2001) state that good teaching encourages the deep learning approach in students and discourages the surface approach. If one accepts this, the extent to which students score high on the deep approach and low on the surface approach (on an instrument such as the Revised Study Process Questionnaire, R-SPQ-2F) is indicative of success in encouraging good learning practices and motivations.

Emirati students are often described as having superficial learning goals and strategies (King, 2011; Swan, 2012). These students have been described as: over reliant on memorization; ill equipped for independent learning as a result of teaching practices that do not favour student autonomy; having a passive teacher centred (spoon-fed) learning style and holding teachers responsible for their learning (King, 2011). Such descriptions seem to suggest that teaching practices and other educational conditions in the UAE have encouraged Emirati students towards a surface approach.

However, certain questions may be asked in relation to the above characterizations. First, would a group of Emirati students show a clear tendency towards the surface approach over 
the deep approach using an instrument such as the R-SPQ-2F? Is the deep versus surface approach construct an appropriate model for the UAE given its differences to other learning settings? Finally, what in addition to deep versus surface learning motivations and strategies, may be at play? The research presented here sets out to answer these questions.

\section{2) Literature Review}

\section{a) Learning as dimension constructs}

The deep and surface learning approach constructs alone represent a dichotomized view of learning. Learning approaches under the surface approach are characterized by the need to perform in relation to others in terms of external factors such as grades. Conversely, deep approach students are intrinsically motivated towards the learning content and have content mastery goals (Entwistle and McCune, 2004).

In terms of motivation, the deep versus surface approach construct can be linked to Marsh et al's (2003) learning and performance orientations to study. They state students with the learning orientation are focused towards mastering tasks and increasing competency and knowledge; they tend to see learning as an end in itself; believe that sufficient effort will result in better academic performance; aim to improve new or existing skills overtime; focus on the quality of improvement; have a sense of intrinsic value; and have long-term commitment to academic excellence. On the other hand, the performance orientation is focused on social comparison processes in which the individual works to do better than other students or to attain success based on little effort. It also involves a desire to gain positive judgments and avoid negative judgments of one's competence, external evaluations of self, orientation 
towards the extrinsic value of performance as a means to a desired goal, and the belief that ability is a fixed attribute that cannot be altered by effort (Marsh et al, 2003).

The deep and surface approach learning distinction initially linked deep learning with intention to understand and surface learning was the intention to reproduce. Later, the finding that motivation was correlated with strategies led to the categories being relabelled approaches to learning (Entwistle \& McCune, 2004). Biggs (1987), in his description of the principles underling the Study Process Questionnaire (the precursor to the R-SPQ-2F), describes surface motivation as instrumental where the main purpose is to meet minimal requirements while not working too hard. Surface strategies are reproductive primarily involving rote memorizing. Deep motivation, conversely, is intrinsic and is based on the desire to actualize interest and competence in particular academic subjects. Deep strategies are described as meaningful and involve strategies such as reading widely and interrelating with previous knowledge (Biggs, 1987).

The surface approach is characterized by strategies for content reproduction (Lyke and Kelaher Young, 2006). Rehearsal strategies which involve reading or repeating ideas over and over are favored under the surface approach. These strategies can themselves be broken down into shallow and deep. Shallow rehearsal involves simple repetition whereas deep rehearsal involves association learning where the learner employs mnemonic devices which require a secondary level of processing. Surface strategies (rehearsal and deep rehearsal) are helpful for managing information that is needed for recall on a short-term basis useful for certain types of assessments (Lyke and Kelaher Young, 2006). 
Deep strategies, conversely, are more likely to be chosen in courses that offer more authentic assessment strategies such as projects and papers that require students to make sense of the material. These strategies tend to be generative in nature and require the student to use more sophisticated and elaborate schema in organizing and integrating information (Lyke and Kelaher Young, 2006). Elaboration is a deep strategy which involves assigning meaning to new information by associating it with prior information. Organizational strategies are used to create easier comprehension of new material. This may include outlining main ideas, sketching an information scheme, tabulating information, making outlines, charts and concept maps (Lyke and Kelaher Young, 2006; Guven, 2008). Comprehension monitoring strategies involve learning techniques applied by students to accomplish learning goals by developing their own learning strategies. Finally, affective strategies help students to overcome emotional obstacles that emerge during learning. These strategies include minimizing the fear of failure, decreasing anxiety, motivating oneself or eliminating distractions from learning (Guven, 2008).

Biggs, Kember \& Leung (2001) state that the aim of good teaching is to encourage students to take a deep learning approach (with its associated strategies) and to discourage a surface approach. However, the deep approach does not necessarily equate to better classroom performance. Deep approach learners may not perform better when assessment favors the surface approach and those who score high on the deep approach do not necessarily put more effort into their study (Entwistle and McCune, 2004).

A student's strategic orientation and motivation towards performance also contribute to academic success. A term used to describe this domain in learning is achieving. Biggs (1987) 
defines the achieving domain as being based on competition and ego enhancement. The student with an achieving orientation works to achieve high grades whether or not he or she finds the learning material to be interesting. The strategic focus in the achieving student causes them to organize their time and workspace in order to obtain desired outcomes. Achievingoriented students select whatever strategies they see as most effectively leading to desired outcomes. This is distinguished from the surface approach where the purpose is to meet minimal requirements and strategy is limited to rote learning of essential content for the purpose of getting by (Biggs, 1987).

Several learning approach research questionnaires have been developed to measure student motivation and strategies. Among the instruments intended for higher education there is considerable overlap, particularly in terms of the deep and surface approach distinction (Entwistle and McCune, 2004; Richardson, 2004). Richardson states that across learning inventories convergent validity is good - that there is considerable overlap in the constructs the instruments purport to measure. However, according to the author, the evidence for construct validity (that instruments actually measure what they are purport to) is weaker.

Another criticism of such instruments is that they are based on Western concepts of education which may not neatly apply to other cultural contexts (Smith, 2005). Richardson (2004), in particular, critiques learning approach inventories for not taking into account differences in culture and even changes over time. He warns that instruments whose constructs were validated in one place and time may not be valid in another place and time. He emphasises that 
each research instrument needs to be revalidated from scratch in each context in which it is used.

Higgis (2003) proposes that the learning approaches model is derived from a simplified, quantitatively biased and elitist notion of learning and education. She contends only the most ardent of academic practitioners (such as those who investigate learning approaches) could ever be expected to adopt the deep approach exclusively. Given the understandings, expectations and obstacles faced by under-graduate students the model has been inappropriately applied to such students. In their response to Higgis' critique Marshall and Case (2005) state that it remains nevertheless the goal of higher education to encourage understanding over recall. Thus, investigating learning approaches and encouraging deep learning remain valid goals in educational research and practice.

One instrument widely used in learning approach research has been the Study Process Questionnaire (SPQ) which purports to measure student learning along the deep, surface and achieving dimensions (Entwistle and McCune, 2004; Richardson, 2004). In 2001, Biggs, Kember \& Leung introduced the instrument used in this study, the Revised Study Process Questionnaire (R-SPQ-2F). This is a revision of the original SPQ from three dimensions down to two (deep and surface without the achievement dimension). The number of questions in the instrument was also reduced from 42 to 20 . The main justification for the revision was that a shortened version would enhance utility for diverse teaching environments. However, Richardson (2004) suggests an additional reason for the achievement factor having been removed was that it was less statistically robust. 


\section{b) The current context}

This study was conducted in a national context where formal education is a relatively recent introduction for most of the local population. In 1972, when the UAE gained independence, there were few schools and no colleges and universities. The bulk of the population was illiterate. Since then, with national policy emphasizing education, remarkable progress has been made in reducing the illiteracy rate. With less than 20 percent of the population literate prior to independence, by 2000, 75 percent for women and 70 percent for men were classified as literate (Clarke, 2006).

Of the current population of one million UAE nationals, 250,000 are school children in the K-12 education system. At the tertiary level, about 35000 attend one of three publically funded tertiary institutions set aside for Emiratis (the Higher Colleges of Technology, UAE University and Zayed University). In addition, about 5000 UAE nationals study in private educational institutions or as overseas students in America, Britain and Australia (Godwin, 2006).

The college which is the context of this study is part of a government funded network of career preparation colleges distributed throughout the United Arab Emirates. The students were mostly male UAE nationals and occasionally students from other Gulf State nations. Students tended to come to the colleges upon graduation from high school. There were also some mature students attending evening classes and students sponsored by government departments and corporations. The network to which this college belongs is one of the three major government supported tertiary institutions set aside for Emirati students. The language 
of instruction at the college is English and the students who participated were attending English for academic purposes courses.

Research into learning motivation and strategies has generally occurred in Western educational contexts and there has been little such research in the Gulf States region. Characterizations of student learning approaches in the UAE such as those in the introductory section of this article are mostly antidotal rather than empirically based.

Fields (2011) discusses a qualitative study of the English study habits of Emirati tertiary students studying in the UAE. He describes limited cognitive strategies which focused on understanding vocabulary in context while reading, often by using a bilingual dictionary and writing translations directly in the book. Metacognitive strategies were described as almost entirely absent. On the other hand, social-affective strategies were described as the most developed. This study seems to suggest that although Emirati students are poor at managing their own learning they are effective at overcoming emotional hurdles and working with others towards learning.

Additional evidence for the importance of the affective component in Emirati students is provided quantitatively in the current study. Evidence is also provided for the possible existence of independent achieving domain. 


\section{3) Methods and Results}

\section{a) The Revised Study Process Questionnaire (R-SPQ-2F)}

The Revised Study Process Questionnaire (Biggs, Kember \& Leung, 2001) is designed around the construct of learning strategies and motivation divided into the deep and surface constructs. As the name suggests, the Revised Study Process Questionnaire is a revision of the original Study Process Questionnaire (SPQ) from three factors (deep, surface, and achieving) to two, based on factor analysis of items and responses from earlier versions of the questionnaire. Biggs, Kember \& Leung (2001) state that factor analysis indicates the deep and surface factors only (with motivation and strategy subscales subsumed on both factors) best describes student approaches to learning. The dimensions of the R-SPQ-2F are named as Deep Approach (DA) and Surface Approach (SA), with four sub-scales Deep Motive (DM), Deep Strategy (DS), Surface Motive (SM) and Surface Strategy (SS).

\section{b) Questionnaire preparation and implementation}

The first author analyzed a copy of the R-SPQ-2F item by item for problems in wording. Problems addressed included wordings which were phrased in nuances subject to possible misinterpretation by non-native speakers of English or which included themes or concepts that might not translate into the local cultural context. Based on his experience with the local culture, some items were reworded so that their intent would be clearer for translation and more appropriate given the cultural context. For example, the following item was considered problematic since Emiratis do not generally read novels for pleasure:

I find the studying academic topics can at times be as exciting as a good novel or movie. 
The question was therefore reworded:

I find that studying academic topics can sometimes be as exciting as a listening to a good story or a seeing a good movie.

In another item, the phrase passing acquaintance was judged to be slightly ambiguous and possibly problematic for translation:

I find it not helpful to study topics in depth. It confuses and wastes time, when all you need is a passing acquaintance with topics.

It was reworded as:

I find it is not helpful to study topics in depth. It confuses and wastes time, all you need is basic knowledge about the topics.

The revised English version of the questionnaire was translated into Arabic by a professional translation service. The translated version of the questionnaire was then retranslated back into English by an Arabic speaking colleague. Together the first author and the colleague discussed the items as to whether they kept their intended meaning through translation. A few changes to the translated copy of the questionnaire were suggested by the colleague.

The translated questionnaire was trialed with 20 students. Following the questionnaire trial, a second Arab speaking colleague made further modifications in consultation with the first author such that there was high confidence that the intended meanings were clearly translated. 
In the final version of the questionnaire items were written in both Arabic and English. This was so the content of the questions would be clear to the English speaking instructors who would be distributing the surveys to students. As well, instructors could clarify the meaning of items to students when asked. In addition, a few students were likely to have had stronger English than Arabic. These were students who had been educated in English speaking countries and/or who came from families where one of the parents was from outside the Arab world.

The questionnaires were distributed by email to all instructors teaching in the first year English for academic purposes courses. This involved five hundred and twenty one students registered in 32 classes. In total, questionnaire sets for 23 of the 32 classes were received.

The total number of questionnaires returned was 270 . Of these, 18 were excluded for various reasons - 12 due to obvious response setting; 2 for being unfinished; 2 for being exact duplications of one another (where the two questionnaires were submitted together suggesting one was copied from the other) and 2 for giving multiple responses on the same item. The response data of the remaining 252 questionnaires were entered into SPSS software for analysis.

\section{c) Questionnaire construct validity}

Richardson (2004) states that any research instrument should be validated from scratch in each new context in which it is used. One reason for this is that constructs can be interpreted differently across cultures or even between social groups within a given cultural setting. Construct internal reliability is usually measured by Chronbach's alpha. An alpha .60 is a minimally acceptable score (Cohen et al, 2007; Richardson, 2004). 
In the past, the R-SPQ-2F has shown acceptable levels of internal reliability along the primary deep and surface dimension but not for the motivation and strategy secondary dimensions (Table 1, p.23). For this reason Justicia et al (2008) conclude that the R-SPQ-2F represents the two primary factors better than the four sub-factors.

In the current study, alphas were computed for each of the two primary dimensions (deep and surface) as well as the four sub-dimensions.

Table 1 shows the internal reliability Cronbach's alpha scores obtained in the current study along with scores obtained by other researchers who have used the Revised Student Learning Approach Questionnaire. The alpha scores for the current study show relatively strong internal consistency on the deep approach dimension (.791) and weaker (though still marginally acceptable) internal consistency on the surface approach dimension (.604). The surface approach sub-dimensions did not achieve acceptable alphas. Due to their low alpha scores, the secondary dimensions were not used in the analysis.

\section{d) Deep and surface domain data}

The mean for the deep dimension is 3.39 (of 5) (SD .66). The surface dimension mean is 3.07 (SD .58). Both mean scores are above the midpoint (out of 5) on both dimensions. This was visually evident on the scatter plot of individual averages. The greatest number of results fell within the high deep and surface approach quadrant with $40 \%$. Those with high deep and low surface scores were the second largest group with $26 \%$. 
Gijbels et al (2005) refers to research indicating that a profile consisting of high (or low) scores on both the deep and surface approaches dimensions is typical of novice students. The authors also describe such students as disintegrated, dissonant or not yet established.

An alternative explanation is that the dimensions themselves are problematic. Referring back to the Cronbach's alpha scores of internal consistency, the surface approach dimension only achieved a minimally acceptable alpha. It may be that the surface dimension construct, in particular, does not sufficiently represent the complexity of student motivation and strategies for learning in the current context.

In response to the ambiguous results obtained from the deep versus surface approach dimension analysis, the results were subjected to further statistical analysis.

\section{e) Factor analysis}

To help assess what besides the deep and surface learning dimensions may have been important, a factor analysis was conducted.

The Kaisar-Meyer-Olkin measure of sampling adequacy was calculated and produced a measure of sampling adequacy of .770 indicating sufficient sampling size. Principal axis analysis with Varimax rotation identified five factors greater than 1 which explained $32.6 \%$ of the variance in the data set. However, the eigenvalues-greater-than-one rule is known to overestimate the true number of factors in a data set because of sampling effects (Cliff, 1988). Inspection of the scree plot (Figure 1, p. 26) suggested that only four factors should be extracted from the data set, and this was confirmed by the parallel analysis of 1000 random data sets using the program 
written by O'Connor (2000). The factor analysis was again applied selecting for the first four factor sets, which accounted for 30.3 percent of the total variance.

The factors are named based on the wordings of their constituent items (with loading scores of more than .35; see Table 3, p.25). Table 2 (p.24) contains the factor names, weighted means, standard deviations and the alignment of the factors to the deep and surface constructs based on the items they share with each construct.

Factor 1 contains items which taken together suggest an orientation towards desire to master content. Factor 2 has items which relate to positive affective factors in association with task achievement and content mastery. Factor 3 contains items which suggest orientation towards avoiding interacting with course content in any meaningful way while achieving minimal course requirements. Finally, Factor 4 is made up of two items which suggest an orientation towards maximizing efficiency in course activities towards outcomes. It might also be noted that item 15 which is just below the .35 cut off for inclusion in Factor 4 is also representative of the factor. As we can see, the weighted scores are slightly above the midway score of three for factors 1 , and 4 . Factor 3 stands slightly below the halfway point. Factor 2, satisfaction in learning, stands apart as having a score well above the midway point at 3.60 .

These data suggest that the students experienced satisfaction from learning while having motivations and strategies associated with the surface approach. The students indicated an orientation towards externalized outcomes as indicated by the midway point score on the surface approach dimension (3.07). At the same time, they indicated a strong orientation to 
satisfaction from learning as suggested by the relatively high weighted mean score for Factor 2 - Satisfaction in learning (3.60).

\section{4) Discussion and concluding remarks}

In this section we discuss the suitability of the deep versus surface learning approach construct for investigating student learning in the current context and perhaps more widely. The implications of the questionnaire findings for learning approach research in this and similar contexts are also considered. Finally, we will touch on the implications of the findings for teaching in the current context.

Biggs, Kember \& Leung (2001) maintain that good teaching is to encourage students to use a deep learning approach and to discourage them from using a surface approach. If one accepts this position, the extent to which students score high on the deep approach and low on the surface approach would also suggest success in bringing about meaningful learning. However, as also stated, the deep approach does not necessarily equate to better classroom performance (Entnwistle and McCune, 2004).

As well, models of learning developed in Western contexts should not be assumed to transfer neatly to other cultural contexts (Kember, 2000; Richardson, 2004). Kember (2000), for example, found that Hong Kong university students placed heavy emphasis on memorization in conjunction with the intention to understand. He also noted that courses which provide good career preparation were a source of motivation for the students participating in his study. He reported high levels of achieving motive, but that this was frequently social in nature rather than being individual and competitive. 
In the current study, the ambiguous results along the deep and surface dimensions of the RSPQ-2F (both dimensions scoring above the halfway point); and the emergence of Factor 4 (Reduction of involvement to towards assessment outcomes) suggest a more complex approach may be required than that of the two dimensional model underlying the instrument used here.

The achieving domain represents an attempt to reconcile intrinsic motivation and mastery strategies with the practical needs and concerns of students in the often demanding environment of tertiary education. In tertiary settings, students have to prioritize their goals, while focusing their effort and managing their time. It is also possible to argue that one of the functions of tertiary education is to encourage students to develop self-management and strategic skills.

The achieving domain may be more relevant in tertiary contexts which have a vocational focus and which are in cultural contexts that are highly collective. In the experience of the first author, Emiratis have a collective cultural orientation which manifests itself in relatively strong tendency towards conformity (in dress, social customs and, especially, religion). Naffsinger (1995) in a discussion of face in Arab society emphasises the importance of a near perfect social appearance to dignity and stature in society. Applying this characterization to the current educational context, one would expect that Arab students might be highly predisposed towards socially recognized outcomes such as good grades and hence the achievement orientation.

The context of the current study was highly homogenous - almost all participants were Emirati men working towards employment (or advancement) in the UAE government and semi- 
government sector. In this context, conformity and reputation would have been important aspects of individual success. These cultural and contextual factors are likely to have an influence on how students approach their learning and may set them apart from students in other contexts.

Returning to the constructs, the deep, surface and achieving learning domains are not theories of learning in themselves, though they have been influenced by them. As is the case with the deep and surface domains, descriptions consistent with the achieving domain are to be found within learning theory. For example, in social cognitive theory, self-regulation is the process by which students regulate themselves in a 'pro-active' way. Self-regulation refers to the thoughts, feelings and behaviors that contribute to the student's goals. Self-regulated learners set goals and task-related strategies guided by their awareness of their own strengths and limitations (Zimmerman, 2002). Achieving oriented students could be expected to arrange things to make the best use of their strengths while offsetting their weaknesses to achieve the best outcomes. On the motivational side of the achieving domain, there is an apparent overlap with the performance-approach construct of Goal Theory. Performance-approach goals aim at performance for competency gaining reasons but are based on the need to perform well for an audience or in relation to others (Elliot and Church, 1997).

In learning approach research, the deep and achieving approaches have been found to correlate positively (Tait \& Entwistle, 1996; Entwistle, Tait and McCune, 2000; Kreber, 2003). Parallels to this finding are to be found in motivational research. Amabile et al (1994) present evidence that intrinsic and extrinsic motivation are additive. They refer to survey and 
experimental studies which indicate that intrinsic and extrinsic motivation rather than being mutually exclusive coexist and that this coexistence can support learning and complex problem solving skills. Therefore the intrinsic motivation contained within deep learning may be supported (rather than opposed) by the extrinsic motivation of achieving focused learning.

Where the cultural environment is more collective and where one's concept of success is tied to external factors, affect and motivation in learning might also be more closely linked to external indicators of success. It was posited earlier that Emiratis may possess a greater orientation towards collectivism and conformity than is the case in the West. Such a tendency towards conformity and collectivity might, as well, orientate Emirati students towards external outcomes and social achievement. In such a social context the achieving domain may take on an increased significance over that which may exist in the Western context.

Biggs, Kember and Leung (2001) devised the R-SPQ-2F based on factor analysis which suggested that learning approaches are best characterized by two higher order factors - deep and surface. Since then, other research involving the SPQ has also provided evidence for two higher order factors (also termed meaning and reproducing) in which achieving is a sub-factor (Phan and Doe, 2008; Zeegers, 2002). It is not our intention to enter into the debate as to whether there are two or three higher order factors. However, the findings of the current study suggest the emergence of the strategic focus (Factor 4) within the surface domain of the R-SPQ-2F. A fuller picture of this strategy orientation might come out if there if there were specific strategy focused questions in the deep domain of the current questionnaire as well. 
These findings may point to features of student learning which might guide the development of learning approach questionnaires more suited the Arabian Gulf context then the two dimensional model of the R-SPQ-2F . Such an instrument would possibly set out to measure: positive learning affect in students (Factor 2 which is probably associated with both mastery and achievement motivation); the extent students make use of mastery strategies (Factor 1); the extent they employ strategies for achievement (Factor 4 ) and the extent they engage in problematic learning avoidance (Factor 3).

Finally, we will conclude by discussing the relevance of the findings to tertiary teaching practice in the UAE and the Gulf States. The evidence of this study tentatively suggests that the participating students have a strong affective component (tied to learning outcomes) and that achieving goals may be significant. It is also important to consider, as discussed earlier, that higher education is not deeply rooted in the Emirati culture. As such, the more individualistic characteristics of learning associated with the Western model of tertiary education may not translate well to the current context. In the UAE context, a more structured instructional approach is likely to be advantageous. Such an approach may enhance student affect and perceived achievement by providing increased opportunities for content mastery. Content which is presented in a linear and hierarchical format with needed resources, useful information and sub-goals can help to support mastery outcomes. In addition, an instructional approach that has considerable teacher input and feedback would bolster students who are working towards greater independence. Compared to other contexts, high levels of involvement with students may be expected from teachers. This involvement is likely to include 
Student Learning Approaches in the UAE

providing the support needed (feedback, explanation, and, in some cases, intervention) to help students to achieve while learning. 
Student Learning Approaches in the UAE

Table 1 - Cronbach's Alpha Scores Comparison

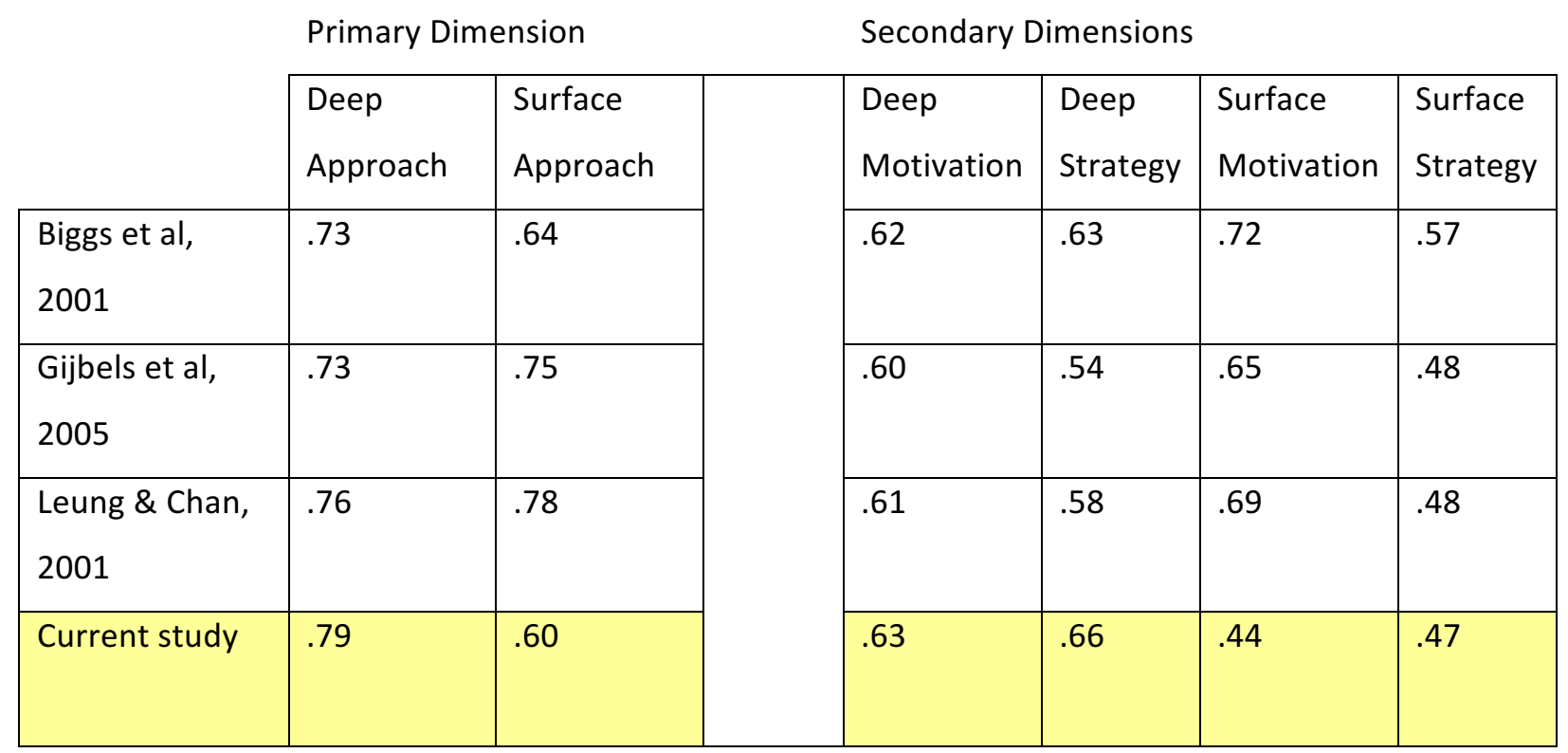


Student Learning Approaches in the UAE

Table 2 - Factory Analysis Summary

\begin{tabular}{|c|c|c|c|c|}
\hline & $\begin{array}{l}\text { Percent of } \\
\text { variance }\end{array}$ & $\begin{array}{l}\text { Weighted } \\
\text { Mean }\end{array}$ & $\begin{array}{l}\text { Standard } \\
\text { Deviation }\end{array}$ & $\begin{array}{l}\text { Construct } \\
\text { of Items }\end{array}$ \\
\hline Factor 1 - Content mastery & 10.54 & 3.17 & 0.78 & \multirow[t]{2}{*}{$\begin{array}{l}\text { Deep } \\
\text { Items }\end{array}$} \\
\hline Factor 2 - Satisfaction in learning & 8.30 & 3.60 & 0.69 & \\
\hline Factor 3 - Learning avoidance & 5.85 & 2.95 & 0.80 & \multirow[t]{2}{*}{$\begin{array}{l}\text { Surface } \\
\text { Items }\end{array}$} \\
\hline $\begin{array}{l}\text { Factor } 4 \text { - Reduction of involvement towards } \\
\text { assignment outcomes }\end{array}$ & 5.63 & 3.23 & 1.07 & \\
\hline
\end{tabular}


Table 3 - Rotated Factor Matrix (scores of more than 3.5 highlighted)

Extraction Method: Principal Axis Factoring

Rotation Method: Varimax with Kaiser Normalization

\begin{tabular}{|c|c|c|c|c|c|}
\hline & \multicolumn{4}{|c|}{ Factor } \\
\hline & & 1 & 2 & 3 & 4 \\
\hline Q1 & Studying tends to give me a feeling of deep personal satisfaction. & .205 & .547 & -.001 & -.082 \\
\hline Q2 & $\begin{array}{l}\text { I find that I have to do enough work on a topic so that I can form my } \\
\text { own opinions and understandings before I am satisfied. }\end{array}$ & .112 & .551 & .092 & -.030 \\
\hline Q3 & My aim is to pass the course while doing as little work as possible. & -.011 & .025 & .403 & .141 \\
\hline Q4 & $\begin{array}{l}\text { I only study seriously what is given out in class or is in the course } \\
\text { outlines. }\end{array}$ & -.163 & .347 & .280 & .224 \\
\hline Q5 & I feel that almost any topic can be interesting once I get into it. & .263 & .415 & -.179 & .156 \\
\hline Q6 & $\begin{array}{l}\text { I find most new topics interesting and often spend extra time trying to } \\
\text { obtain more information about them. }\end{array}$ & .473 & .339 & .045 & -.056 \\
\hline Q7 & $\begin{array}{l}\text { I do not find my course very interesting so I keep my work to the } \\
\text { minimum. }\end{array}$ & -.068 & -.126 & .239 & .232 \\
\hline Q8 & $\begin{array}{l}\text { I learn some things by just memorizing, going over and over them until I } \\
\text { know them automatically even if I do not understand them. }\end{array}$ & .101 & .164 & .497 & .005 \\
\hline Q9 & $\begin{array}{l}\text { I find that studying academic topics can sometimes be as exciting as a } \\
\text { listening to a good story or a seeing a good movie. }\end{array}$ & .293 & .460 & .205 & -.147 \\
\hline Q10 & I test myself on important topics until I understand them completely. & .387 & .390 & -.027 & -.163 \\
\hline Q11 & $\begin{array}{l}\text { I find I can get by in most assessments by memorizing key sections } \\
\text { rather than trying to understand them. }\end{array}$ & .046 & -.069 & .554 & -.028 \\
\hline Q12 & $\begin{array}{l}\text { I generally restrict my study to what is specifically set as I think it is } \\
\text { unnecessary to do anything extra. }\end{array}$ & -.265 & .138 & .199 & .238 \\
\hline Q13 & I work hard at my studies because I find the materials interesting. & .469 & .352 & .035 & -.089 \\
\hline Q14 & $\begin{array}{l}\text { I spend a lot of my free time learning more about interesting topics } \\
\text { which have been discussed in different classes. }\end{array}$ & .636 & .127 & .079 & -.002 \\
\hline Q15 & $\begin{array}{l}\text { I find it is not helpful to study topics in depth. It confuses and wastes } \\
\text { time, all you need is basic knowledge about the topics. }\end{array}$ & -.010 & -.116 & .186 & .327 \\
\hline Q16 & $\begin{array}{l}\text { I believe that the college teachers shouldn't expect students to spend a } \\
\text { lot of time studying material everyone knows won't be examined. }\end{array}$ & -.091 & .103 & .094 & .430 \\
\hline Q17 & $\begin{array}{l}\text { I come to classes with questions about what I am learning. I want to } \\
\text { have answers to these questions so I can better understand what I am } \\
\text { learning. }\end{array}$ & .551 & .126 & -.099 & -.013 \\
\hline Q18 & $\begin{array}{l}\text { I make an effort to do some extra reading (by myself) about the topics } \\
\text { that teacher lectures on in class. }\end{array}$ & .684 & .084 & .018 & -.046 \\
\hline Q19 & $\begin{array}{l}\text { I see no point in learning material which is not likely to be in the } \\
\text { examination. }\end{array}$ & .041 & -.152 & -.025 & .723 \\
\hline Q20 & $\begin{array}{l}\text { I find the best way to pass the examinations is to try to remember } \\
\text { answers to likely questions. }\end{array}$ & -.078 & .093 & .363 & .193 \\
\hline
\end{tabular}


Figure 1 - Scree Plot

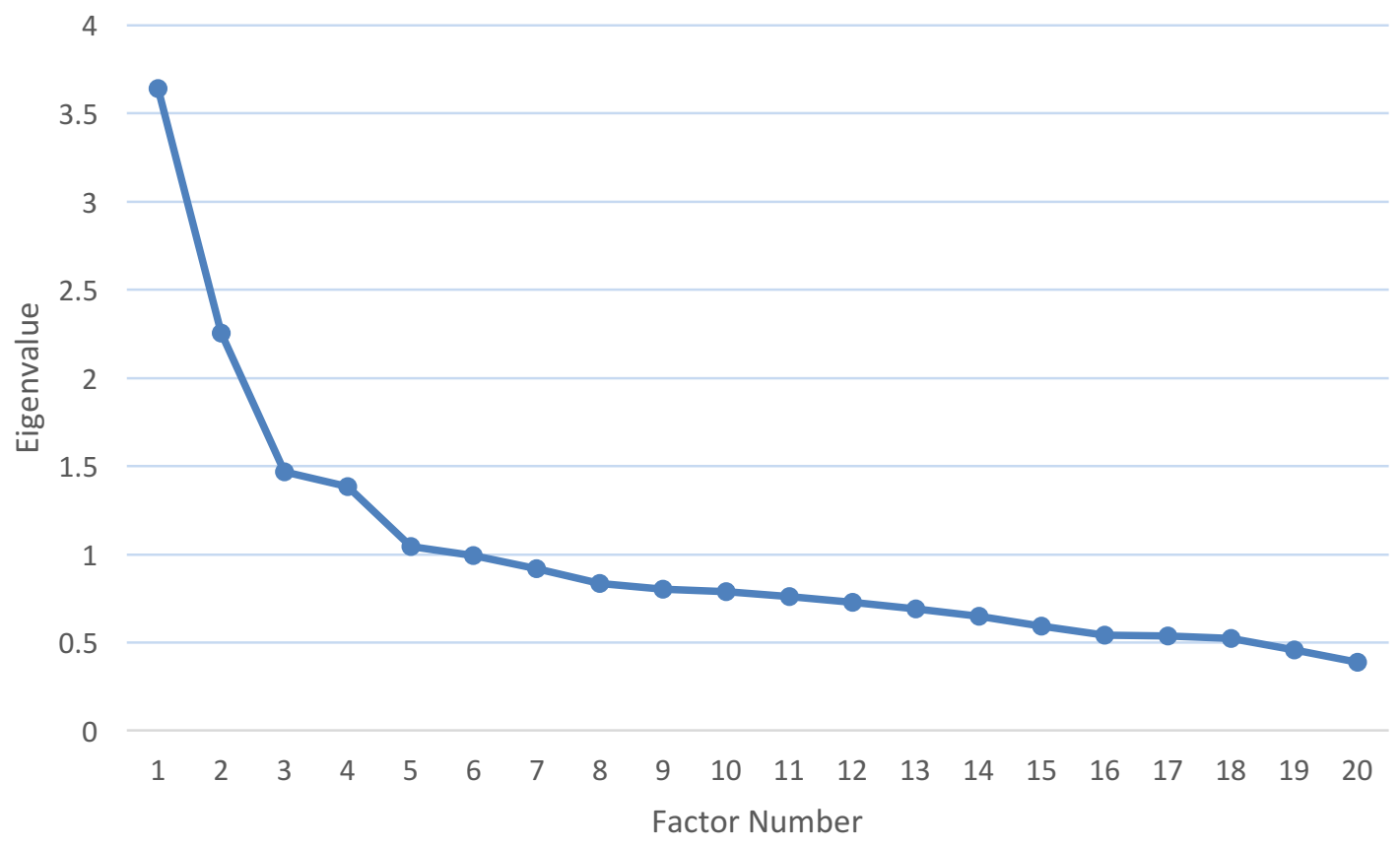

\section{Acknowledgement:}

The authors would like to thank John T.E. Richardson for his advice and assistance in regards to the statistical analysis described in this article. Any errors or omissions are strictly our own. 


\section{Works Cited}

Amabile, T. M., Hill, K. G., Hennessey, B. A., \& Tighe, M. E. (1994). The work preference inventory: Assessing intrinsic and extrinsic motivational orientations. Journal of Personality and Social Psychology, 66(5), 950-967.

Biggs, J. (1987). Student Approaches to Learning and Studying. Melbourne: Australian Council for Educational Research.

Biggs, J., Kember, D., \& Leung, D. (2001). The revised two factor process qestionnaire: R-SPQ-2F. British Journal of Educational Psychology, 71, 133-149.

Clarke, M. (2006). Beyond antagonism? The discursive construction of 'new' teachers in the United Arab Emirates. Teaching Education, 17(3), 225-237.

Cliff, N. (1988). The eigenvalues-greater-than-one rule and the reliability of components',. Psychological Bulletin, 103(2), 276-279.

Cohen, L., Manion, L., \& Morrison, K. (2007). Research Methods in Education. New York: Routledge.

Elliot, A. J., \& Church, M. A. (1997). A hierarchical model of approach and avoidance achievement motivation. Journal of Personality and Social Psychology, 72(1), 218-232.

Elliot, A. J., \& McGregor, H. (2001). A 2X2 acheivement goal framework. Journal of personality and Social Psychology, 80(3), 501-519.

Entwistle, N., \& McCune, V. (2004). The conceptual bases of study strategy inventories. Educational Psychology Review, 16(4), 325-345. doi:10.1007/s10648-004-0003-0

Entwistle, N., Tait, H., \& McCune, V. (2000). Patterns of response to an approaches to studying inventory accross contrasting groups and contexts. European Journal of Educational Psychology, 15(1), 3348.

Fields, M. (2011). Learner motivation and strategy use among university students in the United Arab Emirates. In C. Gitsaki (Ed.), Teaching and Learning in the Arab World (pp. 29-48). Bern: Peter Lang Publishers.

Gijbels, D., Van de Watering, G., Dochy, F., \& Van den Bossche, P. (2005). The relationship between students' approaches to learning and the assessment of learning outcomes. European Journal of Psychology of Education, 20(4), 327 - 341.

Godwin, S. M. (2006). Globalization, education and emiratization, a study of the United Arab Emirates. The Electronic Journal on Information Systems in Developing Countries , 27(1), 1-14. 
Guven, M. (2008). Development of Learning Strategies Scale: Study of validation and reliability. World Applied Sciences Journal, 4(1), 31-36.

Higgis, T. (2003). Constructing images of ourselves? A critical investigation into 'approaches to learning' research in higher education. British Educational Research Journal, 29(1), 89-104.

Justicia, F., Pichardo, C., Cano, F., Berbén, A., \& De la Fuente, J. (2008). The Revised Two-Factor Study Process Questionnaire (R-SPQ-2F): Exploratory and confirmatory factor analyses at item level. European Journal of Psychology of Education, 23(3), 355-372.

Kember, D. (2000). Misconceptions about the learning approaches, motivation and study practices of Asian students. Higher Education(40), 99-121.

King, M. (2011). Implementing problem-based learning in the Gulf: A case study of Arab students. In C. Gitsaki (Ed.), Teaching and Learning in the Arab world (pp. 357-376). Bern: Peter Lang AG.

Kreber, C. (2003). The relationship between students' course perception and their approaches to studying in undergraduate science courses: A Canadian experience . Higher Education Research \& Development, 22(1), 57-75.

Lyke, J. A., \& Kalaher Young, A. J. (2006). Cognition in context: Students' perceptions of classroom goal structures and reported cognitive strategy use in the college classroom. Research in Higher Education, 47(4), 447-490.

Marsh, H. W., Craven, R. G., Hinkley, J. W., \& Debus, L. R. (2003). Evaluation of the big-two-factor theory of academic motivation orientations: An evaluation of jingle jangle faclicies. Multvariate Behavioral Research, 38(2), 189-224.

Marshall, D., \& Case, J. (2005). 'Approaches to learning' research in higher education: a response to Haggis. British Educational Research Journal, 31(2), 257-267.

Naffsinger, P. A. (1995). 'Face' among the Arabs. Retrieved October 25, 2013, from Central Intelligence Agency: https://www.cia.gov/library/center-for-the-study-of-intelligence/kentcsi/vol8no3/html/v08i3a05p_0001.htm

O'connor, B. P. (2000). SPSS and SAS programs for determining the number of components using parallel analysis and Velicer's MAP test. Behavior Research Methods, Instruments, \& Computers, 32(3), 396-402.

Phan, H. P., \& Deo, B. (2008). Revisiting' the South Pacific approaches to learning: a confirmatory factor analysis study. Higher Education Research \& Development , 27(4), 371-383.

Richardson, J. (2004). Methodological issues in questionnaire-based research on student learning in higher education. Educational Psychology Review, 16(4), 347-358. 
Smith, L. (2005). An investigation into student approaches to learning at a multicultural university using the Revised Study Process Questionnaire. In A. Brew, \& C. Asmar (Eds.), Higher Education in a Changing World: Higher Education Research and Development (pp. 553-541). Sidney: HERDSA.

Swan, M. (2012, February 12). Pupils have been cheating 'since kindergarten'. Retrieved from http://www.thenational.ae/news/uae-news/education/pupils-have-been-cheating-sincekindergarten

Tait, H., \& Entwistle, N. (1996). Identifying students at risk through ineffective study strategies. Higher Education, 31(1), 97-116.

Zeegers, P. (2002). A Revision of the Biggs' Study Process Questionnaire (R-SPQ). Higher Education Research \& Development, 21(1), 73-92.

Zimmerman, B. J. (2002). Becomming a self-regulated learner: An overview. Theory into Practice, 41(2), 64-70. 